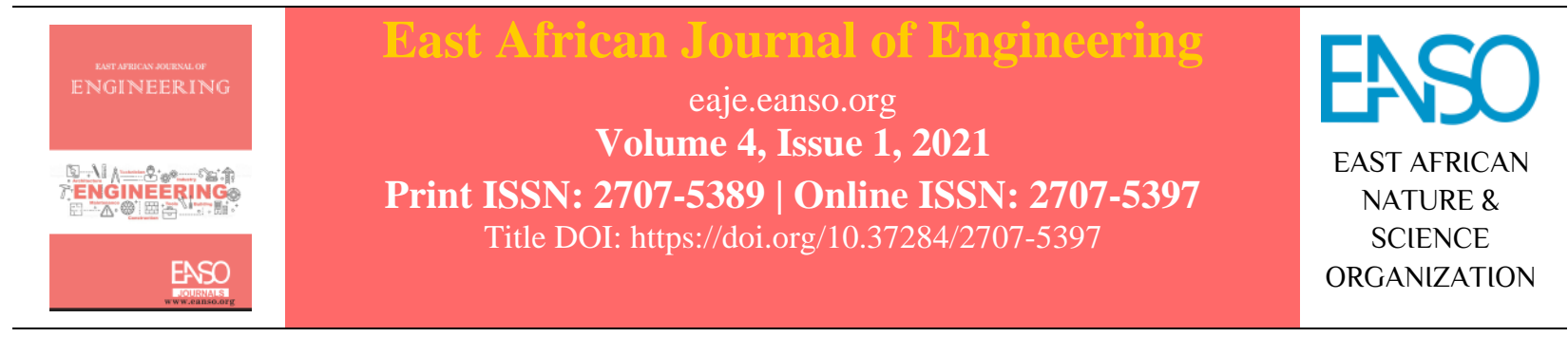

Original Article

\title{
A Mathematical Model on Linkage Leakage in Sewage Pipes Laid in a Porous Ground Using Computation Fluid Dynamics.
}

\author{
Joseph Ebelait ${ }^{l}$, Semwogerere Twaibu, $\mathrm{PhD}^{1 *}$, Moses Nagulama ${ }^{1} \&$ Asaph Muhumuza Keikaral \\ ${ }^{1}$ Busitema University, P. O. Box 236, Tororo, Uganda. \\ * Author for Correspondence ORCID ID: https://orcid.org/0000-0002-7276-844; Email: semwogerere@eng.busitema.ac.ug.
}

Article DOI: https://doi.org/10.37284/eaje.4.1.482

\section{Publication Date: ABSTRACT}

25 November 2021 This study describes the linkage leakage in sewage pipes through a porous media using computational fluid dynamics with the presence of one leak through fluid

Keywords: $\quad$ simulations using the Ansys fluent 17.2 commercial software based on standard $\mathrm{k}-\varepsilon$ model under steady-state condition. The pipe section is three-dimensional

Porous Media, with a pipe length of $40 \mathrm{~mm}$, a pipe diameter of $20 \mathrm{~mm}$, and leak orifice diameter Computational Fluid of $2 \mathrm{~mm}$ with a porous media of length $25 \mathrm{~mm}$ and width $30 \mathrm{~mm}$. The interest of this study was to reduce the rate of sewage leakage in pipes laid underground

Dynamics, by use computational fluid dynamics. The simulation results obtained shows that

Leakages, when the flow is subjected to an outlet pressure between $100000 \mathrm{~Pa}$ to 275000 Ansys Fluent, $\quad \mathrm{Pa}$ the sewage leaks at pressures of $99499 \mathrm{~Pa}$ to $278799.8 \mathrm{~Pa}$ indicating that Flow Rate. increase of outlet pressures increases the pressure at the leak point and also an increase in the inlet velocity resulted into an increase of velocity at the leak point and no significant change in sewage flow rate with increased inlet velocities. Therefore, monitoring of the pressure and velocity fields along the pipeline is an extremely important tool to identify leaks since these fields are affected by perturbations both before the leak point and after the leak point.

\section{APA CITATION}

Ebelait, J., Twaibu, S., Nagulama, M., \& Keikara, A. M. (2021). A Mathematical Model on Linkage Leakage in Sewage Pipes Laid in a Porous Ground Using Computation Fluid Dynamics East African Journal of Engineering, 4(1), $22-32$. https://doi.org/10.37284/eaje.4.1.482

\section{CHICAGO CITATION}

Ebelait, Joseph, Semwogerere Twaibu, Moses Nagulama, \& Asaph Muhumuza Keikara. 2021. "A Mathematical Model on Linkage Leakage in Sewage Pipes Laid in a Porous Ground Using Computation Fluid Dynamics". East African Journal of Engineering 4 (1), 22-32. https://doi.org/10.37284/eaje.4.1.482.

\section{HARVARD CITATION}

Ebelait, J., Twaibu, S., Nagulama, M., \& Keikara, A. M. (2021) "A Mathematical Model on Linkage Leakage in Sewage Pipes Laid in a Porous Ground Using Computation Fluid Dynamics”, East African Journal of Engineering, 4(1), pp. 22-32. doi: 10.37284/eaje.4.1.482. 


\section{IEEE CITATION}

J., Ebelait., S. Twaibu., M. Nagulama., \& Keikara, A. M. "A Mathematical Model on Linkage Leakage in Sewage Pipes Laid in a Porous Ground Using Computation Fluid Dynamics," EAJE, vol. 4, no. 1, pp. 22-32, Nov. 2021.

\section{MLA CITATION}

Ebelait, Joseph, Semwogerere Twaibu, Moses Nagulama, \& Asaph Muhumuza Keikara. "A Mathematical Model on Linkage Leakage in Sewage Pipes Laid in a Porous Ground Using Computation Fluid Dynamics.” East African Journal of Engineering , Vol. 4, no. 1, Nov. 2021, pp. 22-32, doi:10.37284/eaje.4.1.482.

\section{INTRODUCTION}

Sewage is a type of wastewater that is produced by a community of people. It is characterized by a rate of flow, physical condition, chemical and toxic constituents, and its bacteriologic status. It consists mostly of greywater, Blackwater; soaps and detergents; and toilet paper. Proper collection and safe, nuisance-free disposal of the liquid wastes of a community are legally recognized as a necessity in an urbanized, industrialized society.

Sewer and water leakages in pipes laid underground have become a critical issue for water management authorities in most developed countries and developing alike worldwide. Leakages in sewer and water pipelines may lead to several problems such as a shortage of drinking water, groundwater contamination, and ground subsidence (Karoui et al., 2018). Numerous countries are investing a considerable amount of their annual budget towards the prevention and control of the probable effects of sewer and water pipeline leakage. These issues further aggravate infrastructure and environmental conditions that support human socioeconomic activities. In recent years, developed countries, such as the United Kingdom, Australia, France, Spain, and the United States of America, have experienced a shortage in domestic water supply because of leaking pipe mains (Oren \& Stroh, 2012). The aftereffects of these leakages in pipelines cause ground subsidence and sinkholes (Kwak et al., 2015). These sinkholes result in damage to infrastructure (roads, highways, railways, and underground fluid transportation networks).

Rapid urbanization is associated with increasing resistant surface area which results in increased surface overflow and urban flooding, channel erosion, increased health risk to humans and liquid life due to accumulated trash and dust, decreased time of concentration, reduced groundwater recharge, and subsequent good failures (Ritter et al., 2002). ("United States Environmental Protection Agency," 2012) stated that stormwater overflow causes damage to the nation's waterways. To manage these harmful effects of stormwater overflow, Low Impact Development and Best Management Practices are often used. The pipeline system is one of the most commonly used methods of fluid transportation all over the world. Research on urban sewer pipelines focuses on hydraulics such as pipe slopes and flow rate so that sewage and faecal sludge are to be delivered efficiently (Semwogerere et al., 2020). The flows at the proximity of these structures are typically highly turbulent and often characterized by changes between the open channel and pressurized conditions. Such turbulent flows frequently involve complex interactions between air and water (Lopes, 2013), as in the case of manholes with multiple flows in pipes, stepped channels, and flow network structures. The latter structures are typically composed of an entrance manhole and inflow, overflow, and underflow conduits. The main design and the challenge of the network structure is the allowance of overflows only after underdrain capacity is exceeded while minimizing head losses that reduce the underdrain flow capacity.

(Duchene et al., 1994), experimentally found that a leaking pipe draining into a surrounding gravel trench can be treated as an orifice. However, the published experimental data that supports the orifice hypothesis covers only a limited number and range of parameters (Murphy et al., 2014). More complex 
coupled partial differential equation models (Siwoń, 1987), have also been considered, but are of restricted practical use to stormwater management engineers due to their complexity, and they do not provide a method for calculating the required leaking pipe size (Guo et al., 2006). Computational models for leaking pipe drains with aggregate are typically developed for specific flow geometry, soil, and a limited range of pipe lengths (Fenner, 2000), and are thus difficult to generalize.

Computational fluid dynamics (CFD) seems to be a promising technique to overcome these limitations. It solves the hydrodynamic equations by taking into account a given filter geometry while also permitting visualization of the inner velocity field within the different filter components. A threedimensional numerical model based on computational fluid dynamics (CFD) is an effective alternative to time-consuming and costly traditional experimental investigations. Well-posed 3D CFD models can accurately predict the flow characteristics in a Combines Sewer System (Shepherd et al., 2001). Previous studies have shown that the CFD model could assist in design optimization of a municipal sewage system providing detailed flow fields inside of the system of interest without scale effect e.g. stormwater detention tank; sediment trap and interceptor (Gupta et al., 2020); combined sewer overflow chamber and hydrodynamic separator.

The goal of this research is to present an algorithm for the optimization of sewer pipeline leakages using the open-source CFD software ANSYS FLUENT (ANSYS Inc., 2018), and it is chosen because of its various useful features like porous underground flow, free-surface tracking, and multiphase flow modelling and its ability to analyse a wide range of incompressible and compressible flows, laminar and turbulent flows, and steady-state or transient problems. Therefore, this study discusses the optimization of sewage pipeline leakages and presents the algorithm based on the mathematical description of the processes in sewage pipeline leakages under porous grounds using Computational Fluid Dynamics (CFD).

\section{MATERIALS AND METHODS}

\section{Mathematical Model Formulation}

Three dimensional (3D) numerical simulations was carried out to simulate flows through the porous soils and a leak for the geometry described by (Murphy et al., 2014), using ANSYS FLUENT version 17.2 (ANSYS Inc., 2018). ANSYS FLUENT is a finite volume based CFD model which discretizes the domain into a finite set of control volumes and general conservation equations for mass, momentum, energy etc., are solved on this set of control volumes. FLUENT control volumes are cell-centred and FLUENT is chosen because it has modelling capabilities for a wide range of incompressible and compressible flows, laminar and turbulent flows and steady state or transient analyses. It has the ability to model complex geometries and it has various useful features like porous media flow, free-surface tracking and multiphase flow modelling.

\section{Governing Equations}

For all types of fluid flows, ANSYS FUENT solves mass conservation and momentum conservation equations. Additional equations are also solved when the flow is turbulent (ANSYS Fluent Tutorial Guide 18, 2018). Equations for mass and momentum conservation for phase flows are given in Equations (1) and (2) respectively. $\frac{\partial \rho}{\partial t}+\frac{\partial \rho u_{i}}{\partial x_{i}}=\mathbf{0}$ 
$\frac{\partial\left(\rho u_{i}\right)}{\partial t}+\frac{\partial \rho u_{i} u_{j}}{\partial x_{j}}=-\frac{\partial p}{\partial x_{i}}+\frac{\partial}{\partial x_{j}}\left[\mu\left(\frac{\partial u_{i}}{\partial x_{j}}+\frac{\partial u_{j}}{\partial x_{i}}\right)\right]-\frac{\partial \rho u_{i}^{\prime} u_{j^{\prime}}}{\partial x_{j}}+\rho g_{i}+F_{i}$

These equations are called Reynolds-average Navier Stokes (RANS) equations where instantaneous quantities i.e., velocity, pressure and other scalar quantities are decomposed into mean and fluctuating components. In these equations, $\boldsymbol{\rho}$ is the density of fluid, $\mathrm{u}$ is time averaged velocity, $\boldsymbol{i}, \boldsymbol{j}=\mathbf{1 2 3}$ represent Cartesian coordinates system, $\boldsymbol{k}$ represents turbulent kinetic energy per unit mass, $\overrightarrow{\boldsymbol{u}_{\boldsymbol{\imath}}^{\prime} \boldsymbol{u}_{\boldsymbol{J}}}$ are the Reynolds stresses, $\boldsymbol{\mu}$ represents fluid dynamic viscosity, $\mathrm{p}$ is the static pressure, $\boldsymbol{\rho g}$ is the gravitational body force, and $\mathrm{F}$ contains model dependent source terms such as porous media terms along with external body forces.

\section{Turbulence Modelling}

RANS (Reynold's Average Navier-Stokes) equation-based models are used to model steadystate turbulent flow simulations. The RANS turbulence equation based on the $k-\varepsilon$ standard model, provides fairly reasonable result and is also the most widely used in engineering turbulence modelling for industrial applications, since it is numerically robust and proven to be stable according to Jujuly (2016). This model is based on the eddy or turbulent viscosity concept $\left(\mu_{t}\right)$ where the effective viscosity, $\mu_{\{m e f f\}}$, accountable for turbulence. Therefore, the model assumes that the turbulent viscosity $\mu_{t}$ is related to the turbulent kinetic energy and dissipation through the following ratio as seen in Equation (3).

$\mu_{t}=\frac{\rho c_{\mu} k^{2}}{\varepsilon}$

Where $c_{\mu}$ is a typical model constant with default value of 0.09 to flow with high Reynolds number according to the Ansys fluent theory guide.

This model solves different transport equations where the turbulent kinetic energy $k$, defined by the variation of the velocity fluctuations and can be described as in Equation (4).

$$
\frac{\partial(\rho k)}{\partial t}+\nabla \cdot(\rho u k)=\nabla \cdot\left[\left(\frac{\mu_{e f f}}{\sigma_{\varepsilon}}\right) \nabla k\right]+P_{k}-\rho \varepsilon
$$

\section{Porous Media Model}

The porous media models for single phase flows and multiphase flows use the Superficial Velocity Porous Formulation as the default. Ansys Fluent calculates the superficial phase or mixture velocities based on the volumetric flow rate in a porous region. The porous media model is described in many ways for single phase flow; however, it is important to note that the Superficial Velocity Porous Formulation generally gives good representations of the bulk pressure loss through a porous region. However, since the superficial velocity values within a porous region remain the same as those outside the porous region, it cannot predict the velocity increase in porous zones and thus limits the accuracy of the model (ANSYS Inc., 2018)

Porous media are modelled by the addition of a momentum source term to the standard fluid flow equations. The source term is composed of two parts: a viscous loss term (Darcy law), and an inertial loss term respectively as in Equation (5).

$S_{i}=-\left(\sum_{j=1}^{3} D_{I J} \mu v_{j}+\sum_{j=1}^{3} C_{i j} \frac{1}{2} \rho|v| v_{j}\right)$

where $s_{i}$ is the source term for the $i^{\text {th }}(x, y$, or $z)$ momentum equation, $|v|$ is the magnitude of the velocity $\mathrm{D}$ and $\mathrm{C}$ are prescribed matrices. This momentum sink contributes to the pressure gradient in the porous cell, creating a pressure drop that is proportional to the fluid velocity in the cell.

The pressure drops that Ansys Fluent compute in each of the three $(x, y, z)$ coordinate directions within the porous region is then given as in Equations (6). 
$\Delta p_{x}=\sum_{j=1}^{3} \frac{\mu}{\alpha_{x j}} v_{j} \Delta n x$

$\Delta p_{y}=\sum_{j=1}^{3} \frac{\mu}{\alpha_{y j}} v_{j} \Delta n y$

$\Delta p_{z}=\sum_{j=1}^{3} \frac{\mu}{\alpha_{z j}} v_{j} \Delta n z$

where $1 / \alpha_{i j}$ are the entries in the matrix $D, v_{j}$ are the velocity components in the $x, y$ and $z$ directions, and $\Delta n x, \Delta n y$ and $\Delta n z$ are the thicknesses of the medium in the $x, y$ and $z$ directions.

At high flow velocities, the constant $C_{2}$ provides a correction for inertial losses in the porous medium. This constant can be viewed as a loss coefficient per unit length along the flow direction, thereby allowing the pressure drop to be specified as a function of dynamic head.

Modelling a perforated pipe eliminates the permeability term and use the inertial loss term alone, yielding the following simplified form of the porous media Equation (7):

\section{Figure 1: Schematic Model Geometry}

$\nabla p=-\sum_{j=1}^{3} c_{2}\left(\frac{1}{2} \rho v_{j}|v|\right)$

or when written in terms of the pressure drop in the $x, y, z$ directions

\section{Geometry}

The first step of simulating a real case scenario is to have our system and domain represent the conditions and dimensions observed in real cases. Since there are plenty of different possibilities of a porous media dimensions, the one most relevant to the local industry in Uganda was chosen.

In this stage, the model is setup first using the data given by the national water and Sewage Corporation on the used buried pipes, which includes the pipe diameter, leak size, operating pressure, and pipe depth. The dimensions of the data are then represented by a geometry created using ANSYS spaceclaim. The geometry was set to be a 3dimensional geometry with two bodies i.e., the pipe and soil as in Figure 1.

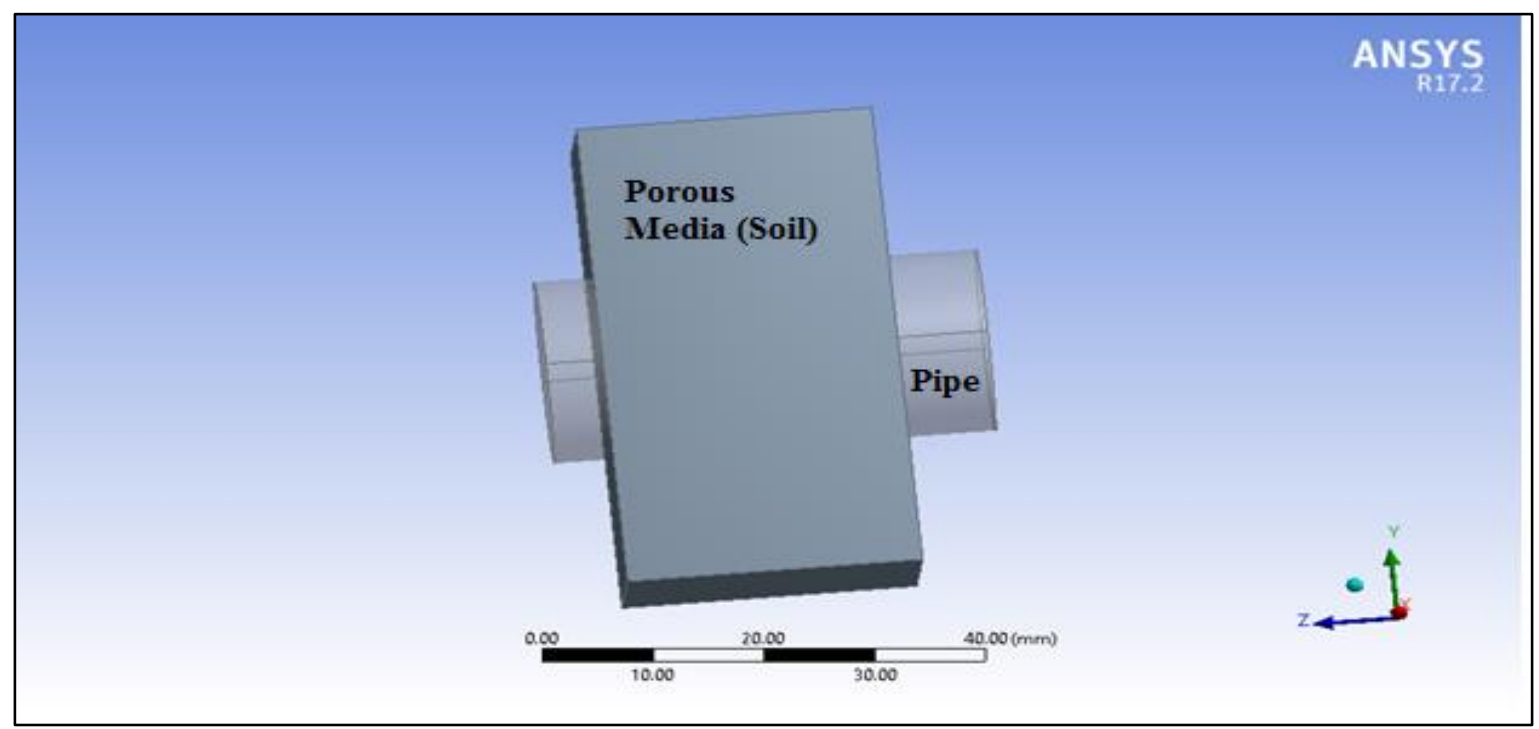

\section{Meshing Sensitivity Analysis}

The next step after creating the geometry is to divide our domain to cells generating a grid. The meshing process was done by using ANSYS Meshing. The system is divided into nodes, and the CFD codes were run at each of these nodes. The size of the 
nodes and the number of the nodes affects the accuracy of the solution, and the computational time it takes to get results. Thus, choosing the optimal mesh size would generate good accuracy with the lowest possible computational time. The size of the mesh is not usually uniform throughout the geometry. It is usually finer around the point of leak and coarser around other locations when the flow is already established. In order to do meshing, the first step was to import the geometry into ANSYS meshing, which was done automatically when using ANSYS Workbench as seen in Figure 2:

Figure 2: Meshed Geometry

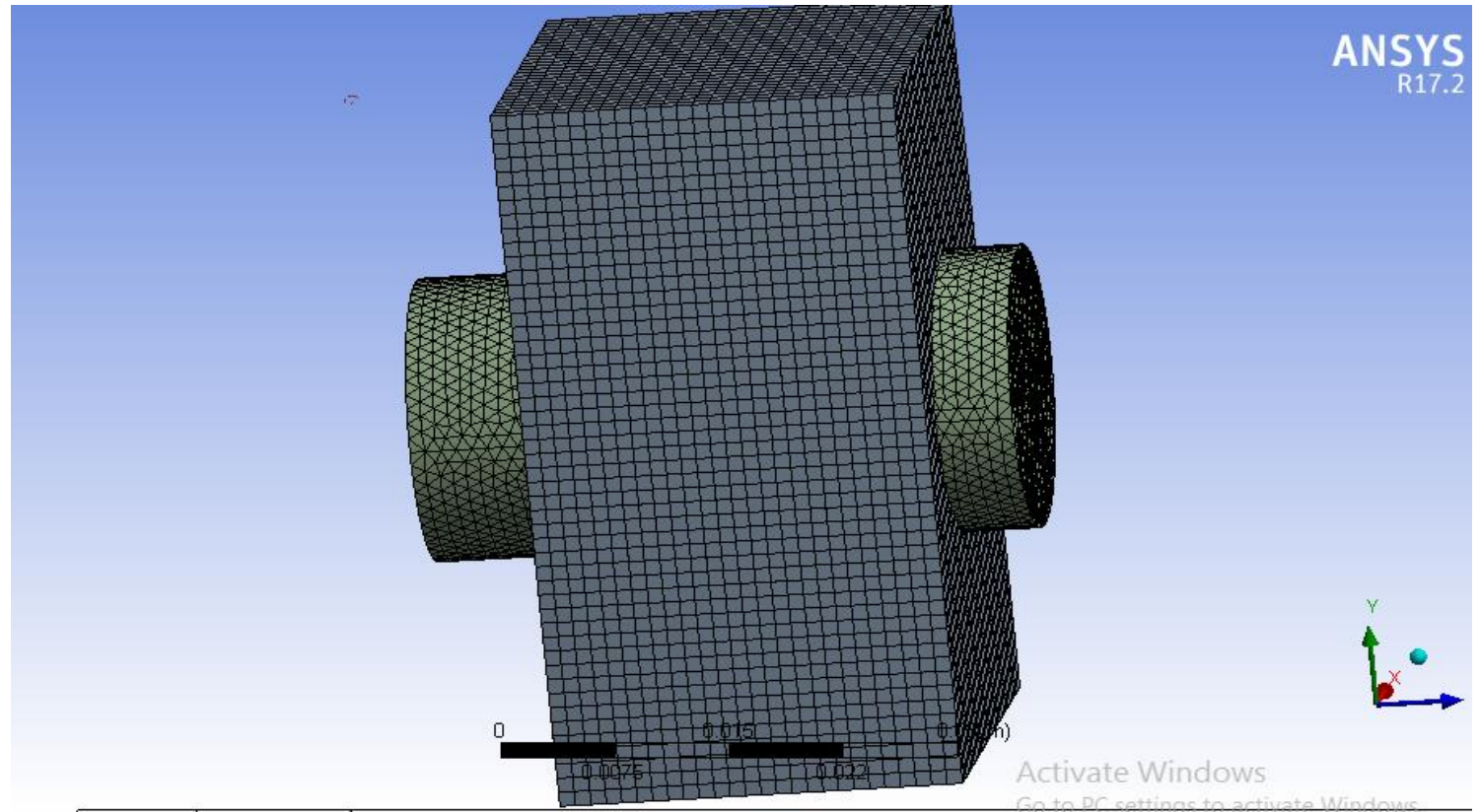

\section{RESULTS AND DISCUSSION}

\section{Pressure and Flow Pattern inside the Pipeline near Leak Orifice}

The pressure contours around the $2 \mathrm{~mm}$ leak orifice for sewage fluids are shown in Figures 3.1 to 3.5 at different operating pressures. The pressure was the same $(\mathrm{OPa})$ throughout at the leak orifice. The pressure contours showed that the pressure increased with increasing operating pressure for sewage flow at the point of leak orifice. The sewage flow within a pipe segment shown a significant pressure change as it flows from inlet to outlet, however, in actual sense; it does decline with a very small magnitude as it flows to outlet as shown in Figures 3 to 7 . At the leakage point, the pressure does reduce extremely i.e., $-2097.4 \mathrm{~Pa}$ to 6414.2 $\mathrm{Pa}$ as depicted in the Figures 3 to 7; however, at the outlet leak point the pressure reduced the more as the sewage fluids entered the soil. This is due to resistance within the porous media (soil); the pressure magnitude is the same all over the soil except near leakage point because the escaping sewage flow from the pipe still has high-pressure magnitude. 
East African Journal of Engineering, Volume 4, Issue 1, 2021

Article DOI: https://doi.org/10.37284/eaje.4.1.482
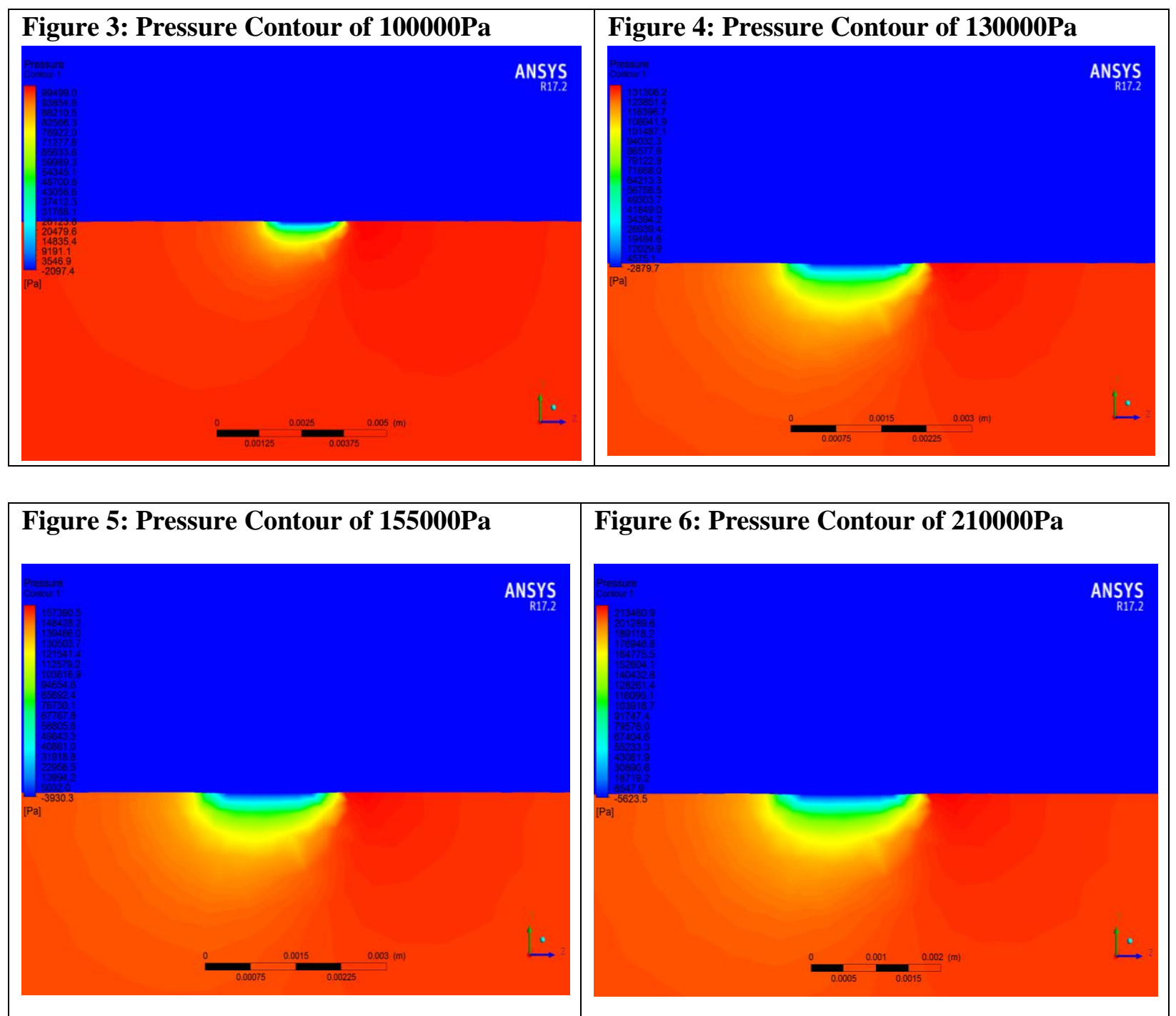

Figure 6: Pressure Contour of 210000Pa

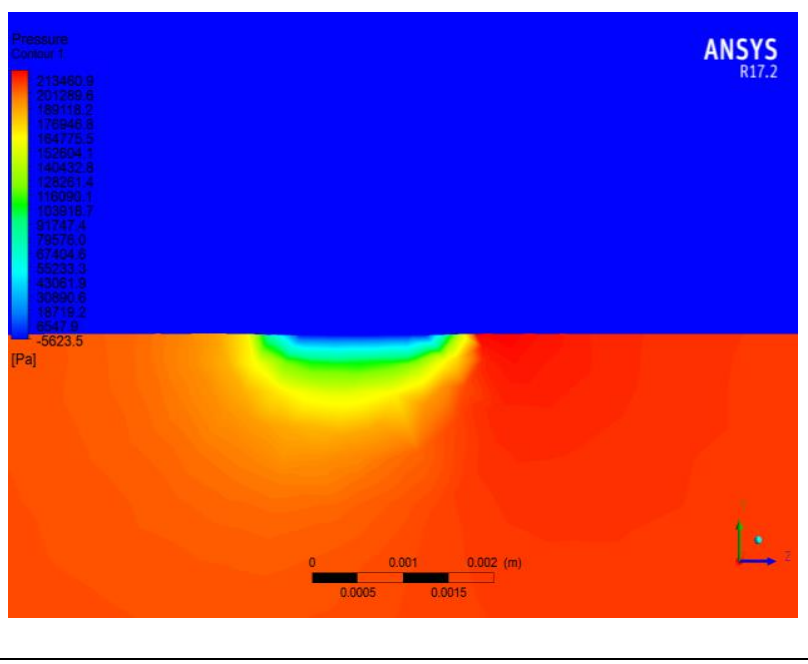

Figure 7: Pressure Contour of 275000Pa

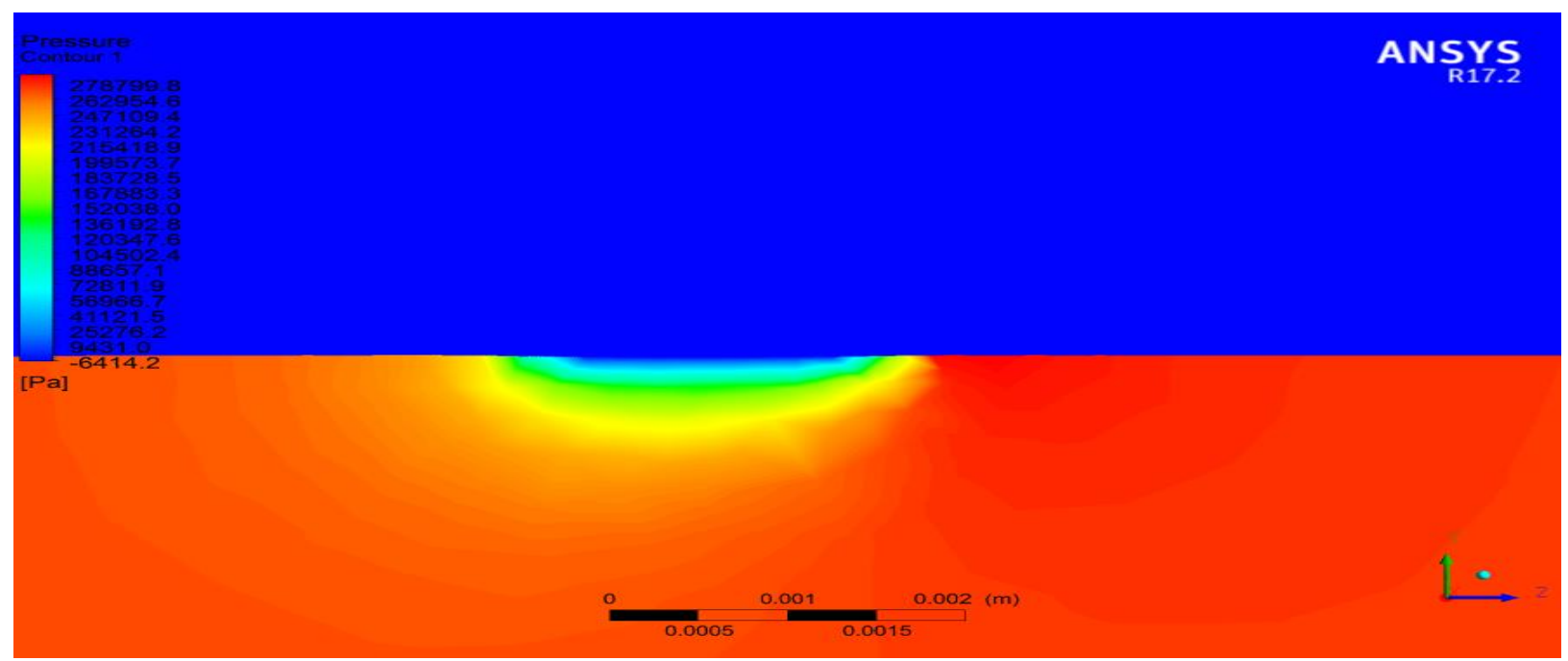

28 This work is licensed under a Creative Commons Attribution 4.0 International License. 


\section{Velocity and Flow Pattern inside the Pipeline} near Leak Orifice

The velocity profile of sewage flow within a pipe segment has no significant change as it flows to the outlet, it later decreases slightly from one segment to another as shown in Figures 8 to 11. At leakage point, the velocity does increase extremely from the pipe dispersing to the soil; at the leak point the dispassion is higher at the point as depicted from the right-hand Figures. 8 to 11 . Also, at all points of the interface between the fluid domain into a pipe and porous outside pipe the velocity has the highest magnitude of flow. Therefore, increasing the velocity at the inlet led to the increase of velocity at the leak point.
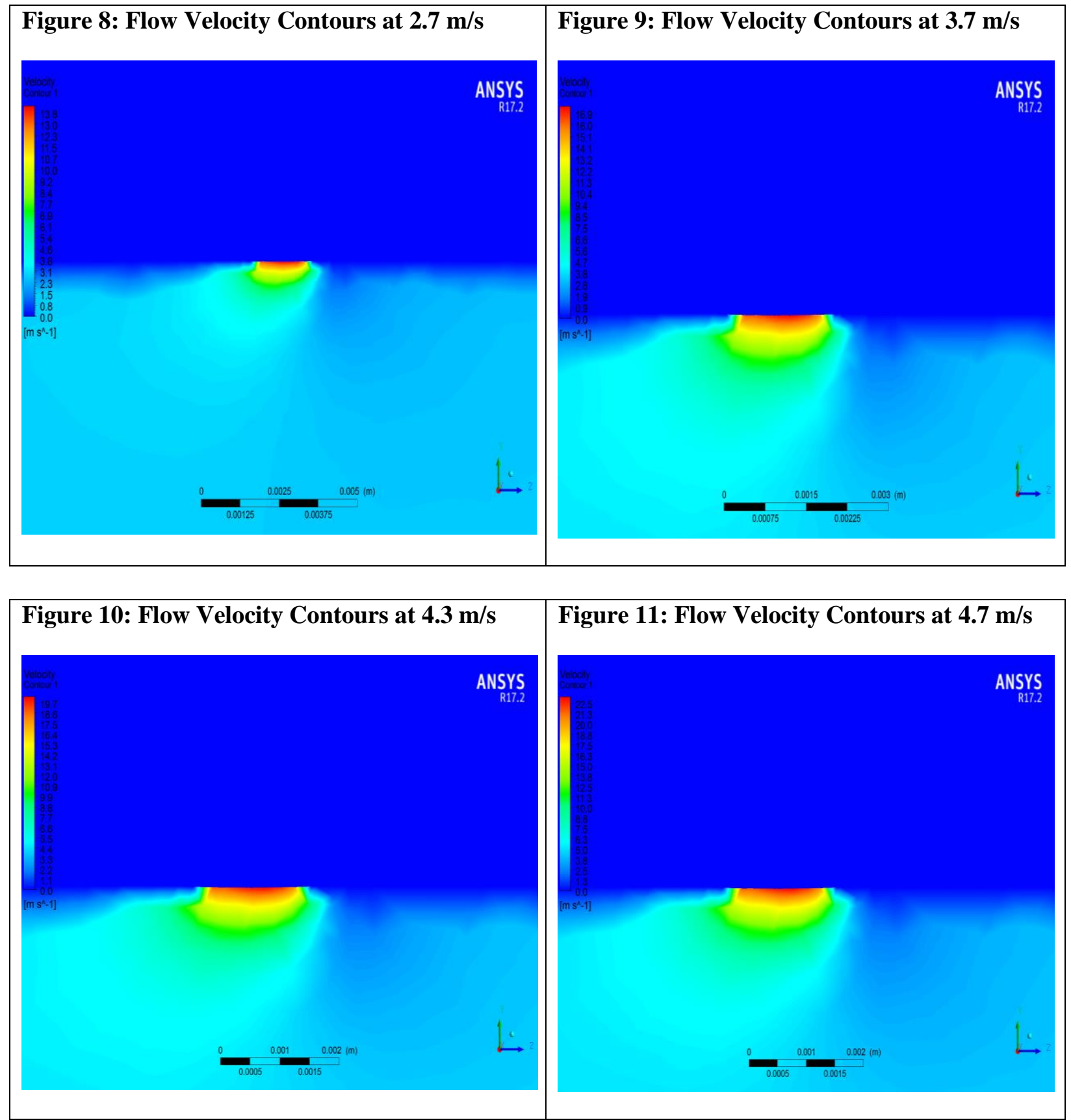

29 | This work is licensed under a Creative Commons Attribution 4.0 International License. 


\section{Effects of Flow Rate at leak orifice through a porous soil}

The fluid flow inside the pipeline was simulated for different velocities under same operating pressure conditions in order to predict the flow rate from the leak orifice that released into the soil. The selected leak size was $2 \mathrm{~mm}$ diameter and the pipe pressure was $3.6542 \mathrm{e}+07 \mathrm{~Pa}$. The ambient pressure was $0 \mathrm{~Pa}$ outside of the leak orifice to simulate hydrostatic pressure.
From the simulation the leakage flow rate increased with a relatively low margin with increased inlet velocity. This is so because we maintained the same diameter of the orifice and also the flow propagation of sewage is different in soil different soil texture. As the grain size becomes smaller, total pore spaces for sewage to flow become limited and have been observed in the velocity vector profiles of the fluids at Figure 12, which present the behaviour of flow velocity at different velocities and same pressure showing no significant change in sewage flow rate with increased inlet velocities.

Figure 12: Leaking Velocity in Relation to the inlet Velocity of $2.7 \mathrm{~m} / \mathrm{s}, 3.7 \mathrm{~m} / \mathrm{s} \& 4.7 \mathrm{~m} / \mathrm{s}$

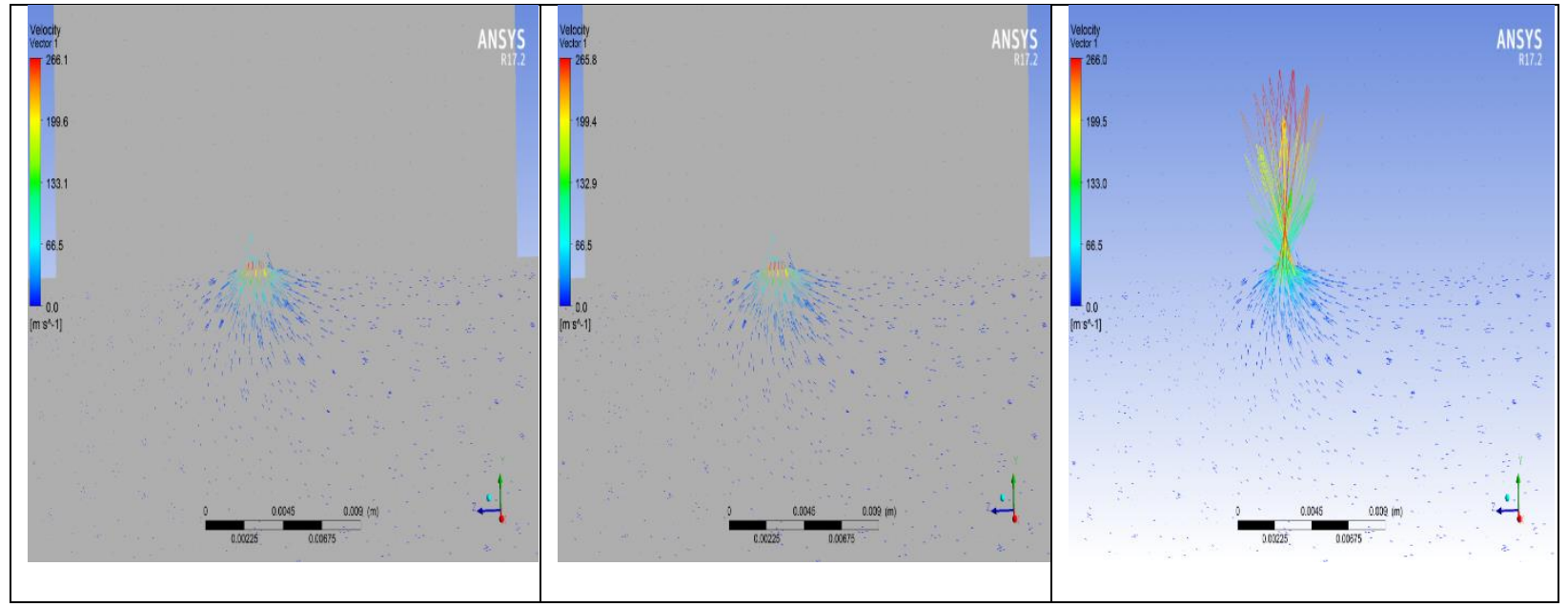

\section{CONCLUSION}

The study was developed numerically using the software ANSYS FLUENT® 17.2 package in a steady state and turbulent conditions. It is possible to conclude that by increasing the inlet velocity of fluid flow, the volume of fluid leaving the orifice (leaking point) is greater and this can affect the hydrodynamics in the point of the leak inside the pipe. Therefore, monitoring of the pressure and velocity fields along the pipeline is an extremely important tool to identify leaks; since these fields are affected by perturbations both upstream and downstream leak positions. In this study, the fluid entering inside the pipe through the inlet is the same as that being released, since no other fluid was modelled outside. Finally, it can be concluded that the importance to use computational tools for optimization purposes in a pipeline, as well as for an analysis and identification of possible problems can arise with time like the wear of the pipeline. Taking this actual study to a more realistic situation in future analysis, the fluid inside the pipe can be changed for different fluid viscosity, investigating how these parameters will affect the leakage flow and its hydrodynamics along the pipeline

\section{Data Availability and Conflicts of Interest}

The data used to support the findings of this study are available from the corresponding author upon request. The authors declare that there are no conflicts of interest regarding the publication of this paper.

30 | This work is licensed under a Creative Commons Attribution 4.0 International License. 


\section{REFERENCES}

ANSYS Fluent Tutorial Guide 18. (2018). ANSYS Fluent Tutorial Guide 18. ANSYS Fluent Tutorial Guide 18, 15317(April).

ANSYS Inc. (2018). ANSYS Fluent, Release 19.1, Help System, Theory Guide. In ANSYS Fluent 19.1.

Duchene, M., McBean, E. A., \& Thomson, N. R. (1994). Modeling of Infiltration from Trenches for Storm-Water Control. Journal of Water Resources Planning and Management. https://doi.org/10.1061/(asce)07339496(1994)120:3(276)

Fenner, R. A. (2000). Approaches to sewer maintenance: A review. Urban Water. https://doi.org/10.1016/s1462-0758(00)00065-0

Guo, Y., Walters, G. A., Khu, S., \& Keedwell, E. (2006). Optimal Design of Sewer Networks using hybrid cellular automata and genetic algorithm. IWA, London, UK., January 2006.

Gupta, P., Alam, J., \& Muzzammil, M. (2020). A simulation and experimental approach for flow through stratified porous media perpendicular to bedding plane. Water and Energy International, $63 r(1)$.

Karoui, T., Jeong, S. Y., Jeong, Y. H., \& Kim, D. S. (2018). Experimental study of ground subsidence mechanism caused by sewer pipe cracks. Applied Sciences (Switzerland). https://doi.org/10.3390/app8050679

Kwak, P.-J., Park, S.-H., Choi, C.-H., Lee, H.-D., Kang, J.-M., \& Lee, I.-H. (2015). IoT(Internet of Things)-based Underground Risk Assessment System Surrounding Water Pipes in Korea. International Journal of Control and Automation. https://doi.org/10.14257/ijca.2015. 8.11 .18
Lopes, P. M. B. (2013). Free-surface flow interface and air-entrainment modelling using OpenFOAM. Wuhan Daxue Xuebao (Xinxi Kexue Ban)/Geomatics and Information Science of Wuhan University.

Murphy, P., Kaye, N. B., \& Khan, A. A. (2014) Hydraulic Performance of Aggregate Beds with Perforated Pipe Underdrains Flowing Full. Journal of Irrigation and Drainage Engineering, 140(8). https://doi.org/10.1061/(asce)ir.19434774.0000740

Oren, G., \& Stroh, N. (2012). Antileaks: A device for detection and discontinuation of leakages in domestic water supply systems. In European Journal For Young Scientists And Engineers.

Ritter, L., Solomon, K., Sibley, P., Hall, K., Keen, P., Mattu, G., \& Linton, B. (2002). Sources, pathways, and relative risks of contaminants in surface water and groundwater: A perspective prepared for the Walkerton inquiry. In Journal of Toxicology and Environmental Health - Part A.https://doi.org/10.1080/152873902753338572

Semwogerere, T., Awichi, R., Lwanyaga, J. D., Noah, E. J., Masanja, V. G., \& Nampala, H. (2020). An Application of Computational Fluid Dynamics to Optimize Municipal Sewage Networks; A Case of Tororo Municipality, Eastern Uganda. Journal Of Advances In Mathematics, 18. https://doi.org/10.24297/jam. v18i.8345

Shepherd, W., Guymer, I., \& Saul, A. (2001). Solute retention and mixing characteristics in CSO structures. Urban Drainage Modeling. https://doi.org/10.1061/40583(275)13

Siwoń, Z. (1987). Solutions for Lateral Inflow in Perforated Conduits. Journal of Hydraulic Engineering. https://doi.org/10.1061/(asce)073 3-9429(1987)113:9(1117)

31 This work is licensed under a Creative Commons Attribution 4.0 International License. 
East African Journal of Engineering, Volume 4, Issue 1, 2021

Article DOI: https://doi.org/10.37284/eaje.4.1.482

United States Environmental Protection Agency. (2012). Proceedings of the Water Environment

Federation. https://doi.org/10.2175/193864705

783867675

32 This work is licensed under a Creative Commons Attribution 4.0 International License. 